\title{
Research On Demand Response Project Based On Price
}

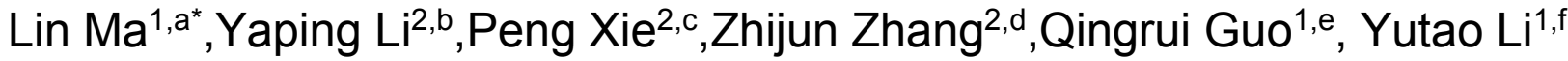

1 State Grid Xinjiang Electric Power Co., Ltd. Electric Power Research Institute,China

2 State Grid Xinjiang Electric Power Co., Ministry of science and technology communication,china

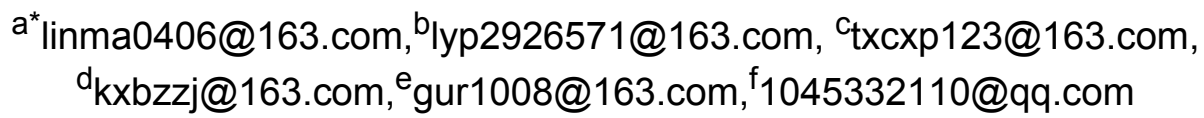

Keywords: automated demand response; time of use pricing; critical peak pricing

\begin{abstract}
In this paper, the characteristics of automated demand response (ADR) are introduced based on OpenADR communication protocol. As a result of domestic and international demand response pilot projects, The implementation of price-based demand response accounts for a large proportion.Based on the automatic demand response and its communication architecture,Domestic and foreign research results were mainly introduced. The automatic demand response project based on Price is elaborated concretely by mainly referring to the successful experiment site or the demonstration project .
\end{abstract}

\section{Automatic demand response and its communication architecture}

Automated Demand Response in the grid side,power suppliers Use advanced measurement system (AMI) to obtain real-time load information of users.At the same time, according to their current electricity generation and power grid operation,transmit the DR information to the electric power terminal device,including electricity price, electric power guidance advice, etc.For the demand side, when receives the DR signal,the terminal device can automatically triggers pre-set programs and responds to power grid DR signals,performs the recommended or mandatory operation of the power grid communication, accesses to electricity subsidies at the same time.The user can opt out voluntarily when the response policy is not accepted. The power grid side and the demand side form a closed loop feedback system, which can effectively guarantee the operation safety of power grid.Both parties can gain the greatest market interest.

Open automatic Demand response (OpenADR) has the following characteristics.

1) Automatic. The response of the OpenADR process does not need manual operation.It triggers the demand side response programs just by receiving DR signal.

2) Open specification.OpenADR uses an open, generic, industry-standard data models to provide a standardized demand response communication and signaling transmission mechanism.

3) Flexible. OpenADR provides flexible, cross-platform, interoperable communication interfaces and protocols.

4) Support for large-scale information transmission.OpenADR transmits DR Signals in different ways.Allows different devices, such as simple bottom devices and complex intermediate devices, to receive DR information that is appropriate for their behavior.

\section{2 price-based demand response projects}

\subsection{Demand response based on peak-Valley time-sharing electricity price}

Compared with other price-based demand response, time period and electricity price are relatively fixed.it is easier to implement, so it has been widely practiced.

2.1.1 Time Division of peak-valley time-interval electricity price Figure 1 is a regional one-day baseline load graph. 


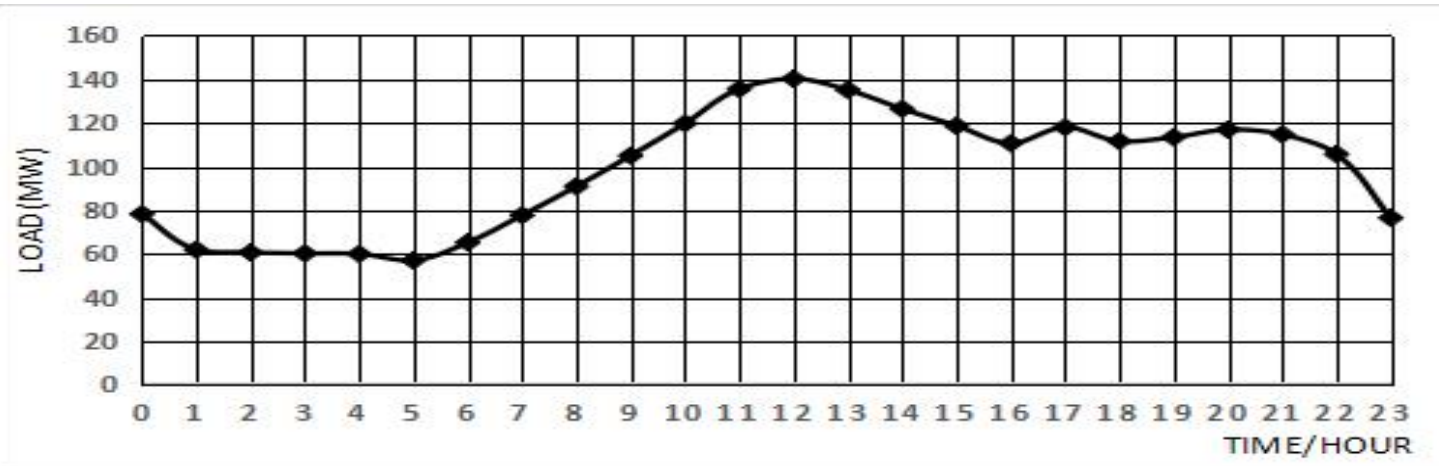

Figure 1 typical daily baseline load curve of a region in summer

The figure shows that the user's power consumption varies greatly during different periods, which is consistent with the actual life.We can qualitatively divide the load curve into three periods: the relatively high "peak period", the relatively low part is "Valley time", the relatively stable part is "peacetime paragraph" [32].

Reasonable division of peak and Valley period is the precondition of setting electricity price. While considering the resource supply of power generation side, the peak and valley period must be in accordance with the peak and valley characteristics of electricity load in this area.Peak and Valley time division of electricity prices are also affected by geographical environment, and some regions of the time Division and seasonal climate, depending on the hydro-electric area will also consider the abundance of water, thus dividing more time [33].Not only that, the grid can also implement different time slots and price floating mechanism for different users.

At present, the following three methods are mainly proposed to divide peak-Valley period:

1) Starting from the user side, according to the trend of the load curve to divide. The paper [34][35] uses the fuzzy half gradient membership function method to analyze the load curve, considering the probability of each point in the curve on the peak, valley and peacetime segment, according to the distribution characteristics of the period division. This approach may encounter situations where it is not possible to determine the period of time according to its membership, and applies only to areas where TOU was first implemented.

2) From the grid side, taking into account the different time period, the installed capacity of power supply and power costs are divided.The literature[36] has established the power supply cost and the load functional relation, considered divides the unit load power supply cost increase curve inflection point achievement the peak valley even time interval the basis. This method implements the time-sharing electricity price to the user to reflect the price of the power supply cost difference function, but can't give full play to the role of the time-sharing electricity price guide requirements.

3) Considers the user demand response the time interval division.Methods (1) (2) divided into the period of time is fixed, the dividing method is difficult to completely adapt to the change of the load.It may appear that divided time unable to correctly follow the load change.In addition, the user load will vary according to the time interval, but the amount of change is not easy to control, so it is necessary to introduce a feedback mechanism to consider the user's response to reasonably divide the period.

\subsubsection{Pricing strategy of peak-valley time-sharing electricity price}

Peak and valley period of pricing ideas mainly have the following two kinds:

1) The research shows that, if the power grid can be taken into consideration in setting up the peak and valley electricity price, the spontaneous electricity cost and the load transfer cost of the high energy consuming enterprise will be considered, and the load transfer decision and the spontaneous electric dispatching decision can be combined with the power grid to bring the power grid and the enterprise a win-win situation.

2) Set up a pricing model based on user demand response. The key point of this model is to reduce the maximum load and load peak-valley difference, so as to obtain the optimal peak-valley electricity price ratio without changing the power distribution revenue and the user's benefit. 
The effect of peak-valley pricing mechanism should be evaluated and optimized comprehensively considering the three factors of peak-Valley electricity, user response and balance of supply and demand.

\subsubsection{Peak-Valley time-sharing electricity price project \\ 2.1.3.1 Time-sharing pricing project in USA}

The U.S. electricity market environment is open. The United States is the first country to implement the demand response project, and it is also the largest and most widely-developed country to implement demand response projects.Currently, 7 regional power systems, including California, PJM and Neu Ying, and other power companies have established demand response projects based on market operations.

The system of time-sharing electricity price in the United States adopts the combination of seasonal price difference and peak-Valley price difference.In order to implement the time-sharing price, it is necessary to install the intelligent electric meter with communication function on the user side.For example, Austin, the capital of Texas, is divided into residential electricity price, small business user price and large business user price.The energy time-sharing Price in Austin is divided into summer and non summer in the season, and is divided into 3 main periods on the same day, as shown in table 1 below [47].

Table I time division of Austin Price

\begin{tabular}{c|c|c}
\hline & Summer (Jun $\sim$ Sept) & $\begin{array}{c}\text { Other seasons (November } ~ \\
\text { May) }\end{array}$ \\
\hline Peak Period & $14: 00 \sim 20: 00$ (Monday to Friday) & none \\
\hline Peace Period & $6: 00 \sim 14: 00 、 \begin{array}{c}20: 00 \sim 22: 00 \text { (Monday to } \\
\text { Friday) }\end{array}$ & Every day \\
\hline Valley Period & $6: 00 \sim 22: 00$ (Weekend) & $22: 00 \sim 6: 00$ (Every day) \\
\hline
\end{tabular}

Visible from the table, Austin only in the summer with the energy concentration and in Monday to Friday only to implement peak period of electricity prices, other seasons only flat, Valley period electricity prices and not week weekend. This is because the Texas summer is very hot, air-conditioning and other large-load electrical appliances in the summer is heavily used, the power grid load, so the power companies need to balance the supply and demand at this time, and the Austin winter temperature is $6.0^{\circ} \mathrm{C} \sim 18.0^{\circ} \mathrm{C}$, similar to the temperature in China's Guangzhou, and its use of warm demand, so This shows that the division of time is not only dependent on a day load changes, but also take full account of the local natural climate and other factors.

In addition to the High-voltage users, other users can voluntarily decide whether to use time-sharing price. Table 2 is the price of electricity pricing standards.

Table II Austin city time share of electricity pricing Table

\begin{tabular}{|c|c|c|c|c|c|c|}
\hline \multicolumn{2}{|c|}{$\begin{array}{l}\text { Monthly electricity } \\
\text { consumption(kWh) }\end{array}$} & $\begin{array}{c}5000 \text { or } \\
\text { less }\end{array}$ & $501 \sim 1000$ & $\begin{array}{c}1001 \sim \\
1500\end{array}$ & $1501 \sim 2500$ & $\begin{array}{l}\text { More than } \\
2500\end{array}$ \\
\hline \multirow{3}{*}{$\begin{array}{c}\text { Summer } \\
\text { electricity prices } \\
(\text { Cents/kWh })\end{array}$} & peak & 9.7 & 11 & 12.2 & 13.1 & 15 \\
\hline & level & 5.1 & 6.2 & 7.1 & 7.9 & 9.5 \\
\hline & Valley & 4.9 & 1.2 & 2.2 & 2.7 & 6.2 \\
\hline \multirow{3}{*}{$\begin{array}{c}\text { Other season } \\
\text { electricity prices } \\
(\text { Cents } / \mathrm{kWh})\end{array}$} & peak & - & - & - & - & - \\
\hline & level & 1.2 & 3.7 & 4.9 & 6.3 & 9.8 \\
\hline & Valley & 0.9 & 0.4 & 0.2 & 0.7 & 4.2 \\
\hline
\end{tabular}

It can be seen from the table that the Austin price is combined with the step electricity price system, and the time-sharing electricity price is related to the monthly electricity consumption. In the table, the 
peak and valley price ratio of summer electricity price is from left to right: 1.9,9.1,5.5,4.8,2.4. In the summer peak, the usual electricity price, the more the use of electricity, the peak, flat electricity prices are more expensive; when the electricity prices in the valley will be increased with the increase in electricity consumption, if continue to electricity, the price would be higher.

The former is not difficult to understand-to restrain users in the peak peacetime section of electricity behavior; the latter is to encourage residents to use electricity, in a certain extent, the price of electricity in the valley is lower, but if not restrained, more and more residents may concentrate on the valley when electricity, this will be counterproductive effect.To this end, the energy consumption exceeds a certain limit, users need to be measured at the time of the Electricity Act. Here, in the valley of electricity consumption in excess of $1000 \mathrm{kwh}$ will increase. Analysis of other season flat valley pricing will also be able to arrive at similar conclusions.

Austin time-sharing Electricity price Project division of more meticulous, it combined with local climate factors and step electricity price mechanism, the summer period made a more reasonable division, but for other seasons should also be divided into peak period appropriate.In addition, although the step electricity price is beneficial to the grid's supply and demand balance, but this more is considers from the power grid side. In the early stages of implementation, it is difficult for users to estimate their electricity consumption and to make reasonable electricity plans. Therefore, it needs a long training time to combine the price of the step electricity price.

\subsubsection{China time-sharing electricity price project}

Take Anhui province as an example, according to the latest information, residential life using two-stage electricity price [44], as shown in table 3.

Table III Household electricity price in Anhui province

\begin{tabular}{c|c|c}
\hline Period & Time division & $\begin{array}{c}\text { Electricity price (yuan / } \\
\mathrm{kWh})\end{array}$ \\
\hline Normal period & $8: 00 \sim 22: 00$ & 0.5953 \\
\hline Valley period & $22: 00$ to $8: 00$ the next day & 0.3153 \\
\hline
\end{tabular}

Other users use the three-stage electricity price, to large industrial users, $35 \mathrm{kV}$ voltage for example [44], the price of the time-sharing electricity as shown in table 4.

Table IV time-sharing electricity price of large industry $(35 \mathrm{kV})$ in Anhui Province

\begin{tabular}{c|c|c}
\hline Period & Time division & $\begin{array}{c}\text { Electricity price (yuan } / \\
\mathrm{kWh})\end{array}$ \\
\hline Peak period & $9: 00 \sim 12: 00 、 17: 00 \sim 22: 00$ & $\begin{array}{c}0.9991(7 \sim 9 \text { months }) \\
0.9425 \text { (Other months) }\end{array}$ \\
\hline Normal period & $8: 00 \sim 9: 00 、 \begin{array}{c}12: 00 \sim 17: 00 、 22: 00 \\
\sim 23: 00\end{array}$ & 0.6310 \\
\hline Valley period & $23: 00 \sim 8: 00$ & 0.3988 \\
\hline
\end{tabular}

In Anhui Province, the electricity price ratio of peace period and valley period is 1.89 . It is estimated that when the trough of electricity consumption accounted for more than $11 \%$ of the total electricity, the implementation of time-sharing electricity prices can save electricity.Residents in the application for the implementation of time-sharing electricity price must pay 150 yuan to transform the energy meter, the monthly power $200 \mathrm{kWh}$, trough power ratio $30 \%$ calculation, it takes 14 months to recover the cost of energy meter renovation, and users in a year can not change the billing method.Large industrial electricity design is very detailed, divided the peak Pinggu three time period, its summer electricity price ratio for peak electricity price: at ordinary times electricity price: Valley when electricity price $=1.58: 1: 0.63$.

In Anhui Province, the time-sharing electricity price policy leaves the user with less profit, the user's cost recovery is long, and the user's appeal is limited. In addition, the time division of the coarse, 
objectively led to the time-sharing Watt-hour meter has not played its due value.In contrast, the large industrial electricity standards in Anhui Province have considered the situation of energy supply in summer, and divided the period in detail, peak and valley ratio up to 2.47. The grid (government) has detailed planning for heavy load users, but it is not enough for the residents. With the involvement of aggregators, the small load on the user side of the population will be aggregated to contribute to the peak.

Through comparison, it can be found that Austin and Anhui province's time-sharing tariff policy has its advantages and disadvantages.Anhui Province can learn from the practice of Austin, to the residents to implement a combination of step electricity price and time-sharing price strategy, so that not only can inhibit peak users of electricity behavior, more important in the trough period can encourage residents to use electricity.

\subsection{Demand response based on real-time electricity price}

The difference between real time electricity price and time-sharing electricity price is that its electricity price is not fixed, but changes with the change of wholesale electricity price. Real-time electricity prices according to the linkage of the wholesale price can be divided into days of real-time electricity prices and real time electricity prices, according to user side implementation time can be divided into a real-time electricity price and two part of real-time electricity price [49].

The real time electricity price is determined by several variables, such as the real-time electricity consumption in the region, the reliable operation constraints of the power system and the power generation and load data of the whole power grid, [50] a mathematical model of real time electricity price is established, which represents the following eight variables:

$$
\boldsymbol{p}_{k, t}=\gamma_{F, t}+\gamma_{M, t}+\gamma_{O S, t}+\gamma_{R, t}+\eta_{L, t}+\eta_{M, t}+\eta_{o s, t}+\eta_{R, t}
$$

In the formula, $\boldsymbol{p}_{k, t}$ is for the K-user in the time period t electricity price; $\gamma$ is the cost of generating electricity, including: marginal power generation fuel cost $\gamma_{F, t}$, generation maintenance cost $\gamma_{M, t}$, power generation quality component ${ }^{\gamma_{o s, t}}$, power generation balance item ${ }^{\gamma_{o s, t}}$, $\eta$ is for transmission cost, including: Marginal net loss cost $\eta_{L, t}$, marginal network maintenance cost $\eta_{M, t}$, network power quality component $\eta_{o s, t}$ and network balance item $\eta_{R, t}$.

\subsection{Demand response and project based on peak electricity price}

Because the electrical network side only appears the peak load in( some) season like summer minority several day-long partial time intervals, therefore, on the basis of rationally establishing the peak-valley price ratio of the time-sharing electricity price, the peak-valley price ratio of these shorter periods can be adjusted higher to motivate the users to reduce the peak period load and receive obvious peak-shaving effect, which is the basic idea of peak electricity price. The peak electricity price can be divided into fixed period peak electricity price, peak electricity price, variable rate peak electricity price and peak subsidy price according to the fixed time period and the peak tariff.

American Bay Electric power Company has implemented the change time interval peak electrovalence in its experiment site( 49). Whole year the peak electrovalence accumulation execution time does not surpass $88 \mathrm{~h}$, but the peak period division is decided by the electricity wholesale market price fluctuation.Its time-sharing electricity price structure: Spike electricity price: peak time Electricity price: at ordinary times electricity price: Valley When electricity price $=6.3: 2.0: 1: 0.76$, visible peak rate is higher than peak electricity price 3 times times above. The project result showed that, the peak time load reduction reaches $44 \%$, the peak time interval load reduction is $21 \%$, the valley time interval load rose $11 \%$, obviously received the peak clipping to fill in the valley the effect.At the same time, this project also promoted this local energy conservation current collector promotion, its whole economic efficiency is huge.

California has implemented a fixed-time and changed period of peak electricity prices, of which peak electricity prices during the change period only to participate in intelligent HVAC projects open to users. The peak electricity price is $70 \%$ higher than the standard electricity price, 1 time higher than 
the off-peak charge price.The results show that the load reduction of fixed-period projects is more than $15 \%$, and the load of change period is about $35 \%$, and the satisfaction of participants is as high as $87 \%$.

In August 2015 in jiangsu province implemented a seasonal peak electricity price policy for the first time [58]. Response to start the condition to reach more than $95 \%$ of the maximum load power load, the actual execution conditions is identified as the second day of nanjing city highest temperature more than $35^{\circ} \mathrm{C}$.Peak period preset to 10:00-11:00 and 14:00-15:00, and no more than 2 times a day, cumulative no more than $2 \mathrm{~h}$.In the peak period, the $315 \mathrm{kVA}$ and above capacity of large industrial users and the central air-conditioning has a separate monitoring of non-industrial users on the basis of peak and valley electricity price per kilowatt hour to increase the price of 0.1 yuan peak tariff policy.

Jiangsu electrical network in August altogether has carried out the seasonal peak electrovalence policy to 56,000 household big industrial enterprises, the peak time interval electric quantity $1,890,000,000$ kilowatt-hours, the peak electric quantity 3.2 hundred million kilowatt-hours which in which execution increases price effectively, increases the peak electrovalence to increase price the income 3200 ten thousand Yuan. The following figure is the load curve of the August 4 14:00-15:00 execution Peak electricity price.

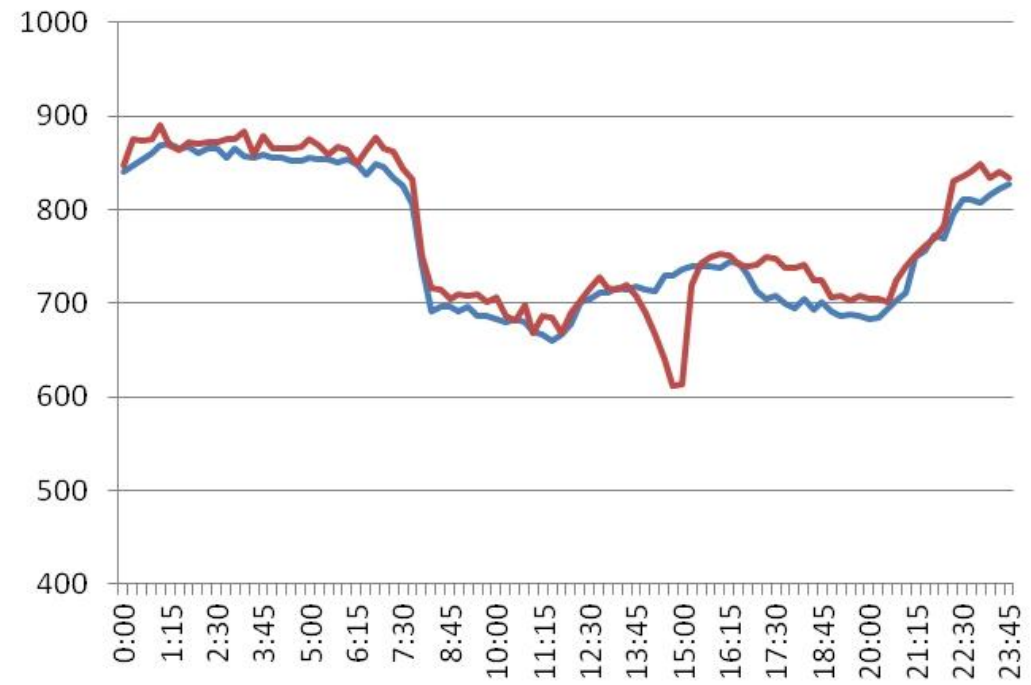

Figure 2. load curve of peak electricity price in Jiangsu power grid

It is shown from FIG. 2 that the response load curve of 14:00-15:00 period shows a significant decrease, which proves the effectiveness of peak electricity price execution. According to the statistical actual response volume of 1.88 million-kilowatt, the response ratio reached more than $26 \%$.

The difference and the effect of the peak electricity price in the Gulf Power Company and Jiangsu power Grid can be seen that the domestic cutting peak project has also received good results. Because the domestic peak rate is far lower than abroad, so the response load ratio is not as high as the foreign projects (44\%).To improve the effect of peak electricity price, it is necessary to improve the pertinence, that is, shorten the execution time and raise the spike rate. In addition, only by taking the temperature as the trigger of peak electricity price is too sensitive, we should combine the forecasting load curve and other factors to decide whether to trigger.

\section{Conclusion}

In this paper, three kinds of demand response based on price are introduced in detail, including peak-Valley time-sharing electricity price, real-time electricity price and peak electricity price.Peak-Valley time-sharing electricity price introduces the period division, pricing strategy and implementation projects at home and abroad.Because the real time electricity price realizes to face many difficulties, at present at home and abroad implements the project to be few, therefore only has introduced its classification and the pricing strategy;Peak-Valley time-sharing pricing introduces the classification, implementation strategy and implementation project, and gives its own opinions and suggestions on the existing problems. 


\section{References}

[1] US Department of Energy.Benefits of demand response in electricity markets and recommendations for achieving them:a report to the United States Congress pursuant to section 1252 of the Energy PolicyAct of 2005[EB/OL]. http://eetd.lbl.gov/ea/ems/reports/congress-1252d.pdf

[2] Fahrioglu M, Alvarado F L. Designing cost effective demand management contracts using game theory[C]// Power Engineering Society 1999 Winter Meeting, IEEE. IEEE, 1999:427-432 vol.1.

[3] Huang H, Li F, Mishra Y. Modeling Dynamic Demand Response Using Monte Carlo Simulation and Interval Mathematics for Boundary Estimation[J]. IEEE Transactions on Smart Grid, 2015:1-1.

[4] Kirschen D S, Strbac G, Cumperayot P, et al. Factoring the elasticity of demand in electricity prices[J]. IEEE Transactions on Power Systems， 2000, 15(2):612-617.

[5] Kim T, Kim S, Shin D, et al. Design and Implementation of an Open, Interoperable Automated Demand Response Infrastructure[J]. Lawrence Berkeley National Laboratory, 2014, 12(4):537-550.

[6] Federal Energy Regulatory Commission. Assessment of demand response and advanced metering: 2006 staff report[ EB/OL].[ 2007-07-21]. http://www. ferc. gov/legal/staff-reports/demand-response.pdf.

[7] Kim H,Kim Y J,Yang K,et al. Cloud-based demand response for smart grid: Architecture and distributed algorithms[C]// Smart Grid Communications (SmartGridComm),2011 IEEE International Conference on. IEEE, 2011:398-403.

[8] National Institute of Standards and Technology. NIST framework and roadmap for smart grid interoperability standards, release 3.0[S].U.S. Department of Commerce,2014.

[9] Kim T, Kim S, Shin D, et al. Design and Implementation of an Open, Interoperable Automated Demand Response Infrastructure[J]. Lawrence Berkeley National Laboratory, 2014, 12(4):537-550. 